\title{
Activation of exchange protein activated by cyclic-AMP enhances long-lasting synaptic potentiation in the hippocampus
}

\author{
Jennifer N. Gelinas, ${ }^{1}$ Jessica L. Banko, ${ }^{2}$ Melinda M. Peters, ${ }^{3}$ Eric Klann, ${ }^{4}$ \\ Edwin J. Weeber, ${ }^{3}$ and Peter V. Nguyen ${ }^{1,5,6,7}$
}

${ }^{1}$ Department of Physiology, University of Alberta School of Medicine, Edmonton, Alberta T6G 2H7, Canada; ${ }^{2}$ Department of Molecular Medicine, University of South Florida College of Medicine, Tampa, Florida 33612, USA; ${ }^{3}$ Department of Molecular Pharmacology and Physiology, University of South Florida College of Medicine, Tampa, Florida 33612, USA; ${ }^{4}$ Center for Neural Science, New York University, New York, New York 10003, USA; ${ }^{5}$ Department Psychiatry, University of Alberta School of Medicine, Edmonton, Alberta T6G 2H7, Canada; ${ }^{6}$ Centre for Neuroscience, University of Alberta School of Medicine, Edmonton, Alberta T6G 2H7, Canada

\begin{abstract}
cAMP is a critical second messenger implicated in synaptic plasticity and memory in the mammalian brain. Substantial evidence links increases in intracellular cAMP to activation of cAMP-dependent protein kinase (PKA) and subsequent phosphorylation of downstream effectors (transcription factors, receptors, protein kinases) necessary for long-term potentiation (LTP) of synaptic strength. However, cAMP may also initiate signaling via a guanine nucleotide exchange protein directly activated by CAMP (Epac). The role of Epac in hippocampal synaptic plasticity is unknown. We found that in area CAl of mouse hippocampal slices, activation of Epac enhances maintenance of LTP without affecting basal synaptic transmission. The persistence of this form of LTP requires extracellular signal-regulated protein kinase (ERK) and new protein synthesis, but not transcription. Because ERK is involved in translational control of long-lasting plasticity and memory, our data suggest that Epac is a crucial link between cAMP and ERK during some forms of protein synthesis-dependent LTP. Activation of Epac represents a novel signaling pathway for rapid regulation of the stability of enduring forms of LTP and, perhaps, of hippocampusdependent long-term memories.
\end{abstract}

Hippocampal area CA1 is crucial for long-term memory (LTM) formation in mice and humans (Zola-Morgan et al. 1986; Tsien et al. 1996). CA1 synapses express persistent alterations in synaptic strength that are thought to underlie memory storage (Bliss and Collingridge 1993; Moser et al. 1998; Abraham et al. 2002; Lynch 2004). Increases (long-term potentiation [LTP]) or decreases (long-term depression [LTD]) in synaptic strength are mediated by complex interactions of intracellular signaling molecules (Sanes and Lichtman 1999; Braunewell and Manahan-Vaughan 2001). 3',5'-Cyclic adenosine monophosphate (cAMP) is a ubiquitous second messenger that is strongly implicated in hippocampal synaptic plasticity and memory. For instance, genetic elimination of calcium/calmodulin-stimulated adenylyl cyclases (AC1 and AC8) blocks late phase-LTP (L-LTP) and LTM for contextual and passive avoidance conditioning (Wong et al. 1999). Similarly, stimulation of cAMP signaling in area CA1 initiates L-LTP (Frey et al. 1993).

Although cAMP-dependent protein kinase (PKA) is typically the primary downstream effector of cAMP, cAMP-regulated guanine exchange factors (GEFs) known as Epacs (exchange proteins directly activated by cAMP) also bind cAMP to diversify its signaling influence. Epacs are expressed in the nervous system (Kawasaki et al. 1998), and they bind cAMP to activate a GTPase, Rap, in a PKA-independent fashion (de Rooij et al. 1998). Because Rap can interact with the Ras/ERK cascade, Epacs can modulate ERK-dependent processes in various eukaryotic cells (Lin et al.

\section{${ }^{7}$ Corresponding author.}

E-mail Peter.Nguyen@ualberta.ca; fax (780) $492-8915$.

Article is online at http://www.learnmem.org/cgi/doi/10.1101//m.830008.
2003; Keiper et al. 2004; Johnson-Farley et al. 2005; Traver et al. 2006).

In the hippocampus, ERK is required for many forms of synaptic plasticity (Sweatt 2004) and can regulate protein synthesis during long-lasting LTP and LTD via phosphorylation of translation initiation factor eIF4E (Banko et al. 2004, 2006; Kelleher et al. 2004; Schmitt et al. 2005). Given the importance of cAMP and ERK signaling in the hippocampus, it is possible that activation of Epac may critically regulate LTP in this brain region as well. However, it is unknown whether activation of Epac can influence hippocampal synaptic plasticity.

We show here that acute perfusion of mouse hippocampal slices with a specific agonist of Epac, 8-(4-chlorophenylthio)-2'O-methyl-cAMP (8-pCPT), enhances the maintenance of LTP in a frequency-dependent manner without affecting basal synaptic transmission or initial LTP induction. This enhancement of LTP stability requires protein synthesis and activation of ERK, but not transcription. Furthermore, application of 8-pCPT leads to a transient increase in phospho-ERK immunoreactivity in hippocampal area CA1. Our data reveal that activation of Epac facilitates LTP in a hippocampal subregion known to be important for the formation of LTMs (Zola-Morgan et al. 1986).

\section{Results}

8-pCPT does not alter basal synaptic properties in area CAl of the hippocampus

As a preliminary step toward characterizing the effects of 8-pCPT in area CA1 of the hippocampus, we examined basal synaptic 
A.

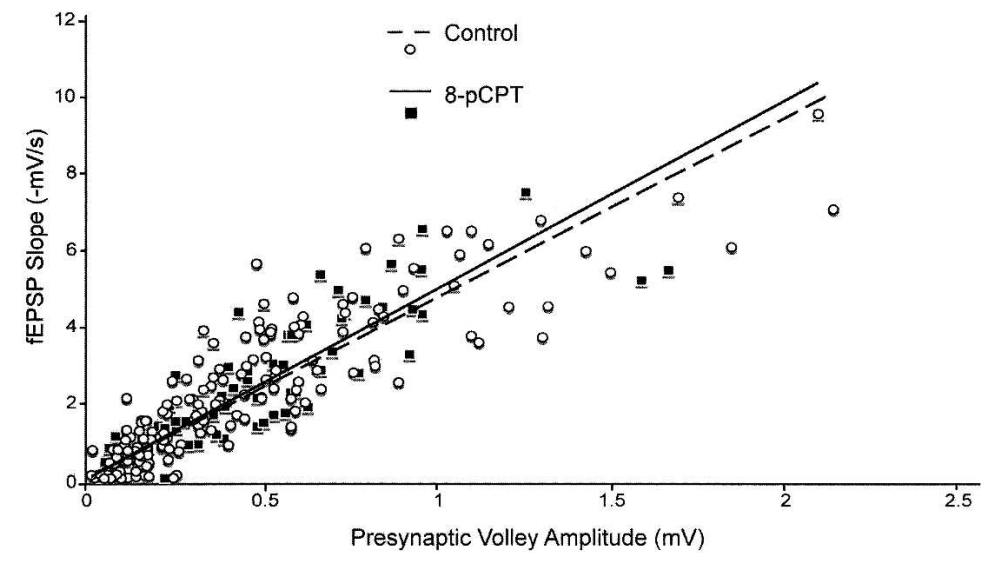

B.

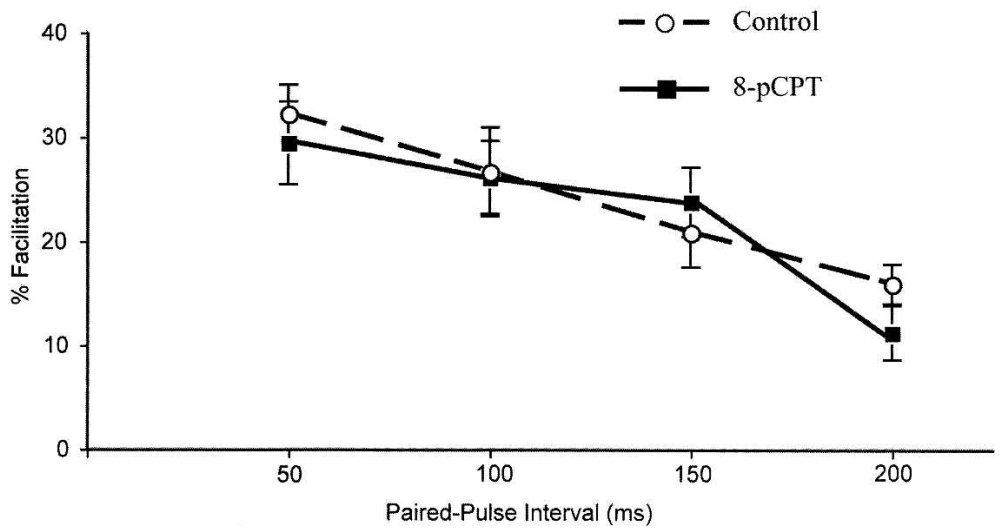

8-pCPT $(100 \mu \mathrm{M})$ to hippocampal slices during baseline test stimuli did not affect synaptic strength during or after drug application (mean fEPSP slopes were $98.0 \pm 6.6 \%$ and $102.8 \pm 4.3 \%$ for control and 8-pCPT-treated slices, respectively, $15 \mathrm{~min}$ after drug application; $P>0.5$; Fig. $2 \mathrm{~A}$ ).

Can 8-pCPT affect LTP induction and maintenance after a stronger, LTPinducing $100-\mathrm{Hz}$ protocol? In area CA1 of the mouse hippocampus, one train of high-frequency electrical stimulation (HFS) at $100 \mathrm{~Hz}$ (1-sec duration) induces an early phase of LTP (E-LTP) that decays to baseline within $2 \mathrm{~h}$ (Huang et al. 1996; Duffy et al. 2001). Applying 8-pCPT during this weak tetanus did not change the initial amount of potentiation generated (mean fEPSP slopes were $219.5 \pm 13.4 \%$ and $224.6 \pm 14.9 \%$ for control and 8-pCPT-treated slices, respectively, $2 \min$ after $1 \times 100 \mathrm{~Hz}$ stimulation; $P>0.5$; Fig. 2B). However, pharmacologic activation of Epac with 8-pCPT during weak tetanus did enhance the maintenance of LTP (mean fEPSP slopes were potentiated to $163.6 \pm 13.1 \% 120 \mathrm{~min}$ after $1 \times 100$ $\mathrm{Hz} ; \quad P<0.01$ compared with $104.3 \pm 9.0 \%$ for controls; Fig. 2B). Application of an Epac agonist increases the stability of LTP generated by one train of HFS without affecting the initial magnitude of potentiation induced by this form of LTP.

\section{LTP elicited by pairing HFS with 8-pCPT requires protein synthesis and ERK, but not transcription}

Long-term stability of synaptic plasticity is associated with de novo protein syn-

function. The relationship between the presynaptic fiber volley and the fEPSP slope was determined over a range of stimulus intensities as a measure of synaptic responsiveness. We observed no differences between these input-output (I/O) properties in 8-pCPT-treated slices and ACSF-treated control slices (8-pCPT, $y=4.9 x, R^{2}=0.80$; Control, $y=4.7 x, R^{2}=0.77 ; P>0.2$; Fig. $1 \mathrm{~A}$ ), indicating that 8-pCPT does not significantly alter basal synaptic transmission.

Paired-pulse facilitation (PPF), a short-lasting presynaptic form of synaptic plasticity and widely used method to infer changes in probability of transmitter release, was not significantly altered by application of 8-pCPT. No significant differences in PPF were observed between ACSF-treated control slices and 8-pCPT-treated slices at 50-, 100-, 150-, or 200-msec interpulse intervals $(P>0.2)$ (Fig. 1B). As such, application of 8-pCPT does not alter basal synaptic properties in hippocampal area CA1.

\section{8-pCPT enhances LTP maintenance, without affecting LTP induction or basal synaptic transmission}

To address whether activation of Epac by 8-pCPT alters longlasting forms of plasticity, we investigated its effects on LTP induction and maintenance. First, we found that application of thesis. The production of new proteins is a key feature of longlasting LTP (Stanton and Sarvey 1984; Deadwyler et al. 1987; Frey et al. 1988; Nguyen and Kandel 1996; Kandel 2001). We tested the hypothesis that activating Epac generates stable, protein synthesis-dependent LTP. One train of HFS applied to area CA1 of the hippocampus elicits decremental LTP that does not critically require protein synthesis. As such, bath application of the general translation inhibitor emetine $(20 \mu \mathrm{M})$ had no significant effect on this form of LTP (Fig. 3A, white circles). However, emetine blocked the enhancement of LTP maintenance induced by pairing 8-pCPT and one train of HFS (mean fEPSP slopes were $109.0 \pm 6.8 \%$ for 8 -pCPT-treated slices $120 \mathrm{~min}$ after $1 \times 100$ $\mathrm{Hz}$ stimulation; $P>0.5$ compared with $104.7 \pm 11.0 \%$ for controls) (Fig. 3A, black squares). Thus, application of an Epac agonist during HFS generates LTP that is stable for at least $2 \mathrm{~h}$ and requires protein synthesis.

We also used a transcription inhibitor, actinomycin D (ActD; $25 \mu \mathrm{M}$ ), to explore the transcriptional dependence of LTP enhancement resulting from Epac activation. Bath application of ActD did not affect the stability of this form of LTP (Fig. 3B). After 120 min, mean fEPSP slopes of 8-pCPT-treated slices were significantly potentiated compared with mean fEPSP slopes from control-treated slices (mean fEPSP slopes were $150.9 \pm 13.4 \%$ for 
8-pCPT-treated slices $120 \mathrm{~min}$ after $1 \times 100 \mathrm{~Hz}$ stimulation; $P<0.02$ compared with $104.7 \pm 10.4 \%$ for controls; Fig. 3B). Thus, pairing 8-pCPT with HFS induces LTP that requires translation, but not transcription.

The ERK signaling pathway is crucial for a plethora of forms of synaptic plasticity (Sweatt 2004; Thomas and Huganir 2004) and is specifically implicated in translational control of plasticity (Banko et al. 2004, 2006; Gallagher et al. 2004; Kelleher et al. 2004). Consequently, we examined the effect of ERK inhibition on our 8-pCPT-enhanced LTP. Because LTP induced by $1 \times 100$ $\mathrm{Hz}$ does not require ERK signaling (Winder et al. 1999), any effects on our LTP can be likely attributed to Epac activation. Bath application of U0126 $(20 \mu \mathrm{M})$, an inhibitor of MEK (the upstream kinase that phosphorylates and activates ERK), blocked 8-pCPTenhanced maintenance of LTP (mean fEPSP slopes were $107.9 \pm 7.1 \%$ for 8 -pCPT-treated slices $120 \mathrm{~min}$ after $1 \times 100$ $\mathrm{Hz}$ stimulation, $P>0.5$ compared with $106.4 \pm 4.7 \%$ for controls; Fig. 3C). Thus, ERK plays a role in Epac-mediated enhancement of LTP maintenance.

To firmly establish that 8-pCPT does not mediate these effects on LTP by activating PKA, we used KT5720 (1 $\mu \mathrm{M})$, a PKA inhibitor. At this concentration, KT5720 blocks maintenance of long-lasting LTP induced by repeated $100 \mathrm{~Hz}$ tetanization of Schaeffer collaterals in mouse slices (Woo et al. 2003). We found that application of KT5720 did not block 8-pCPT-dependent facilitation of LTP maintenance. After $120 \mathrm{~min}$, mean fEPSP slopes of 8-pCPT-treated slices were potentiated to $164.9 \pm 11.0 \%$ compared with $107.9 \pm 7.2 \%$ in control slices $(P<0.01$; Fig. 3D). Thus, 8-pCPT facilitates stability of LTP in a manner that does not critically require PKA. Our findings support the notion that this agonist selectively activates Epac (Bos 2006).

\section{8-pCPT induces ERK phosphorylation in hippocampal area CAl}

Because 8-pCPT-induced enhancement of LTP required ERK, we next examined whether 8-pCPT induces ERK phosphorylation in hippocampal area CA1. We found that 8-pCPT activated ERK, as evidenced by increased phosphorylation of this kinase (phospho-ERK: $P<0.02$ compared with vehicle; Fig. 4A). After 15 min of 8-pCPT incubation, ERK activation became significantly different from control levels. ERK phosphorylation was not significantly different from control levels during drug washout (both at 10 and $30 \mathrm{~min}$ ). Furthermore, ERK activation by 8-pCPT was completely blocked by the MEK inhibitor U0126.

Because pairing 8-pCPT application with HFS generated long-lasting LTP, we also investigated ERK phosphorylation following this paired stimulation protocol. We observed that 8-pCPT did not enhance HFS-induced ERK immunoreactivity, even at an extended time point of 30 min (Fig. 4B). These data suggest that 8-pCPT does activate ERK in hippocambars: $5 \mathrm{mV}, 2 \mathrm{msec}$. pal CA1, but the enhancement of LTP by 8-pCPT is not associated with a further increase in the amount or duration of ERK activation.

\section{LTP generated by pairing 8-pCPT with HFS occludes $\boldsymbol{\beta}$-adrenergic receptor-dependent LTP}

Activation of $\beta$-adrenergic receptors during one train of HFS also enhances the maintenance of LTP by initiating ERK signaling and new protein synthesis (Gelinas and Nguyen 2005). To test the hypothesis that this form of neuromodulatory LTP is mechanistically similar to LTP generated by pairing 8-pCPT with HFS, we used an occlusion protocol. Coapplication of the $\beta$-adrenergic receptor agonist isoproterenol (ISO) and HFS following application of HFS alone did not inhibit the maintenance of $\beta$ adrenergic LTP (mean fEPSP slopes were potentiated to $145.3 \pm 10.1 \% 120 \mathrm{~min}$ after ISO application; Fig. 5A). This result is consistent with the notion that decremental LTP induced by HFS alone recruits intracellular mechanisms that are different from those underlying long-lasting LTP generated by activation of $\beta$-adrenergic receptors during HFS. Thus, $\beta$-adrenergic receptor-dependent LTP can be maintained at synapses previously expressing decremental LTP induced by one train of 100-Hz HFS.

In contrast, coapplication of ISO and HFS following application of 8-pCPT during HFS occluded the maintenance of $\beta$ -

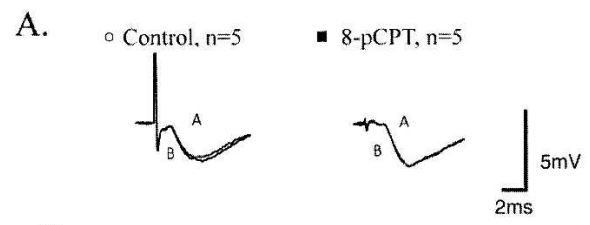

B. Control $+1 \times 100 \mathrm{~Hz}, 8-\mathrm{pCPT}+100 \mathrm{~Hz}, \mathrm{n}=10$ $n=6$
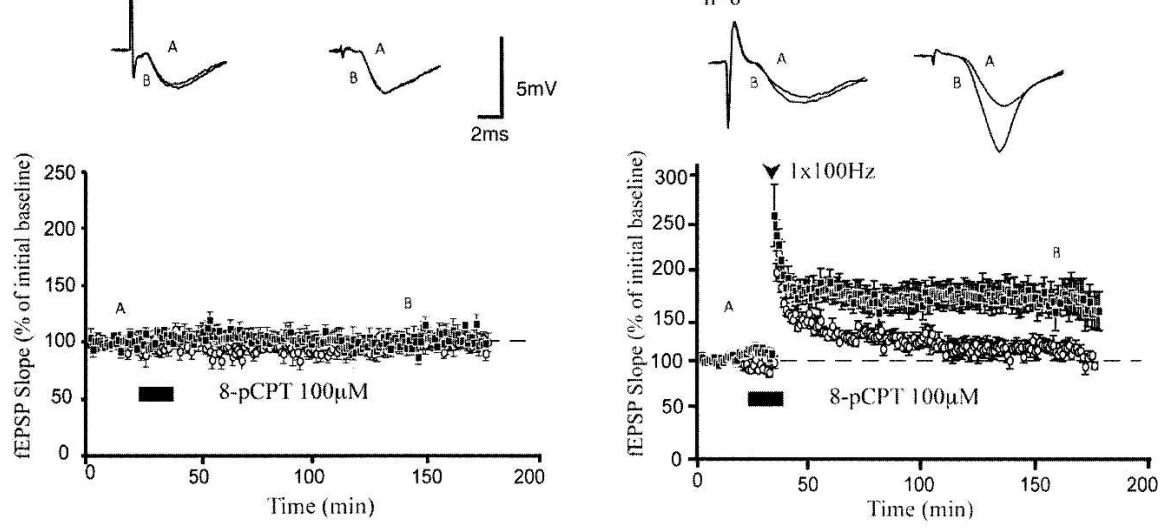

C.

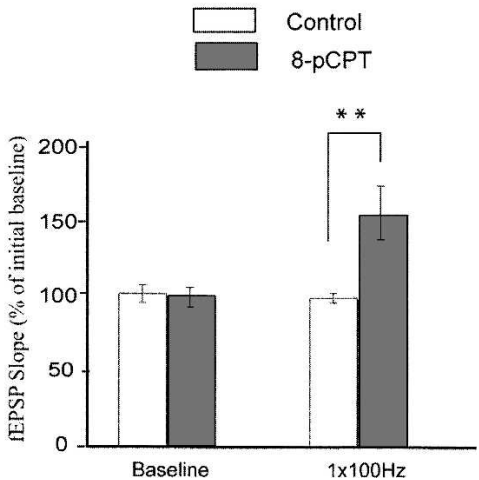

Figure 2. 8-pCPT enhances LTP maintenance, without affecting LTP induction or basal synaptic transmission. (A) Application of 8-pCPT alone has no effect on basal synaptic transmission. (B) Pairing 8-pCPT with $1 \times 100 \mathrm{~Hz}$ stimulation enhances maintenance, but not induction, of LTP relative to controls. (C) Summary histogram for these experiments comparing levels of potentiation 120 min after HFS $\left({ }^{*} P<0.01\right)$. All sample fEPSP traces were sampled at time points A and B on graphs. Calibration 


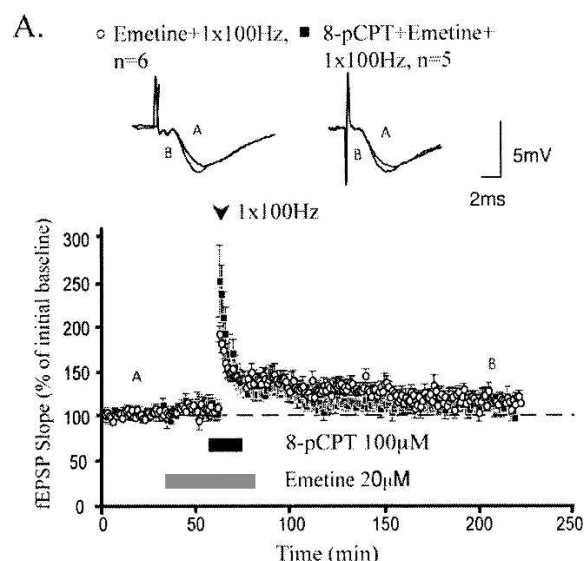

C.
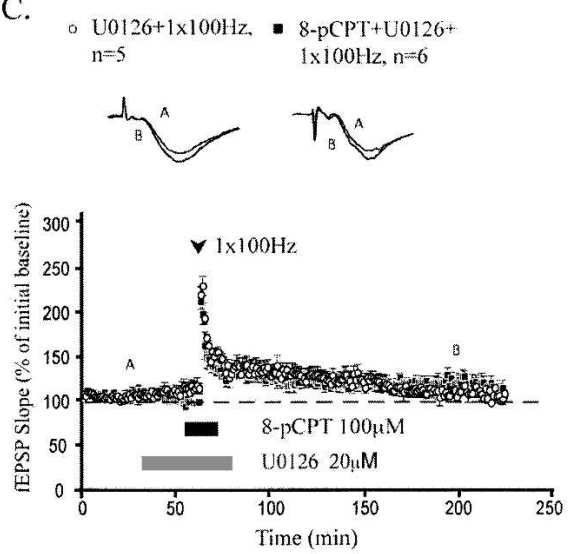

B.

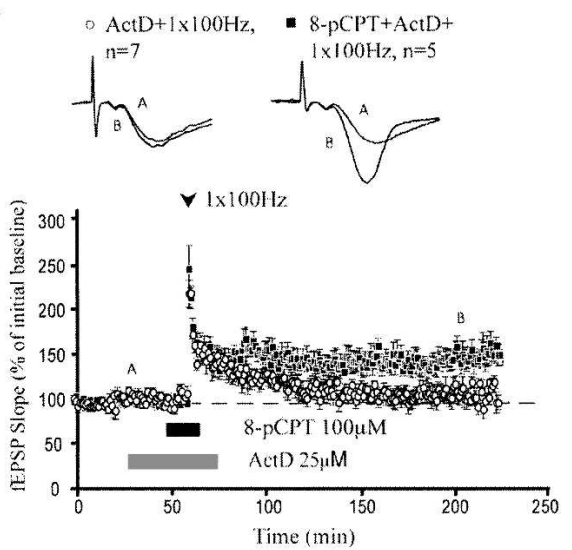

D.
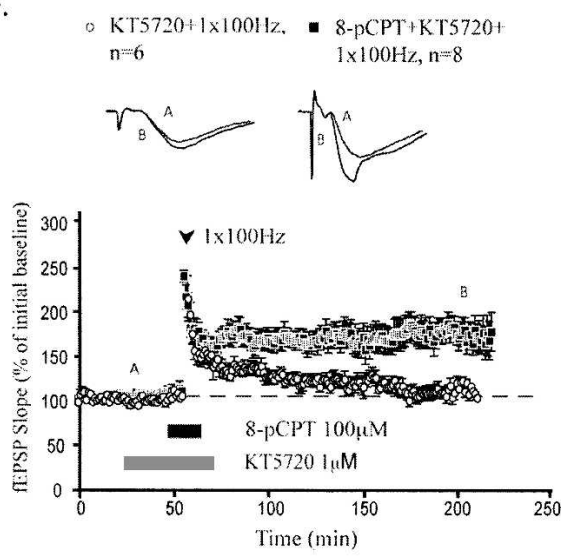

E.

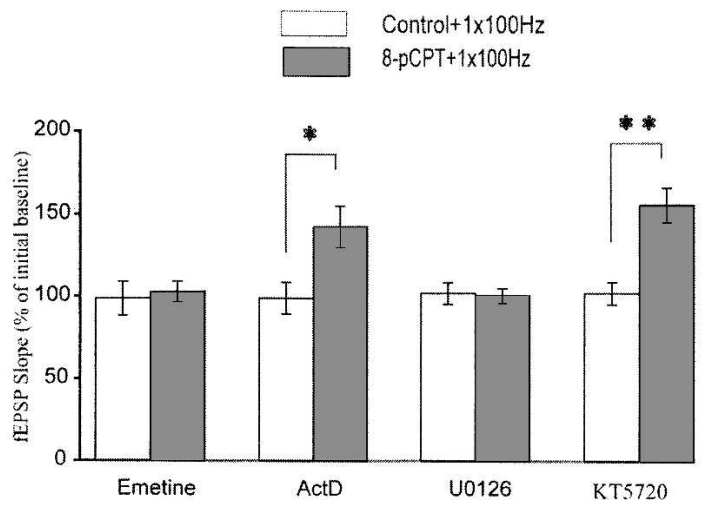

Figure 3. LTP elicited by pairing $1 \times 100 \mathrm{~Hz}$ stimulation with 8-pCPT requires protein synthesis and ERK, but not transcription or PKA. (A) Emetine, a translation inhibitor, blocked the enhancement of LTP by 8-pCPT. (B) Actinomycin D, a transcription inhibitor, had no significant effect on LTP enhanced by 8-pCPT. (C) U0126, an ERK inhibitor, also blocked the enhancement of LTP by 8-pCPT. (D) KT5720, a PKA inhibitor, had no significant effect on LTP enhanced by 8-pCPT. (E) Summary histogram for these experiments comparing levels of potentiation 120 min after HFS $\left({ }^{* *} P<0.01,{ }^{*} P<0.05\right)$. All sample traces were taken at time points $A$ and $B$ on graphs. Calibration bars: $5 \mathrm{mV}, 2 \mathrm{msec}$.

adrenergic LTP (mean fEPSP slopes were $105.2 \pm 5.7 \% 120 \mathrm{~min}$ after ISO application; Fig. 5B). This result suggests that activation of $\beta$-adrenergic receptors and application of 8-pCPT recruit similar mechanisms to facilitate long-lasting LTP. These mechanisms may be substantially engaged by application of 8-pCPT, thereby rendering subsequent activation of $\beta$-adrenergic receptors unable to generate persistent LTP. Overall, these data indicate that acti- vation of either 8-pCPT or $\beta$-adrenergic receptors elicits mechanistically similar forms of long-lasting LTP.

\section{8-pCPT facilitates maintenance of chemically induced LTP}

Because we found that long-lasting LTP induced by activation of $\beta$-adrenergic receptors and 8-pCPT share similar mechanisms, we monitored synaptic strength when 8-pCPT was applied to hippocampal slices during low-frequency stimulation (LFS) (5 $\mathrm{Hz}$ for $3 \mathrm{~min}$ ). This pattern of LFS alone does not persistently alter synaptic strength but permits induction of LTP when $\beta$-adrenergic receptors are concomitantly activated (Thomas et al. 1996; Gelinas and Nguyen 2005). Synaptic responses from slices treated with 8-pCPT did not differ compared with those elicited from control slices (mean fEPSP slopes were $101.1 \pm 5.6 \%$ for control slices and $106.7 \pm 10.5 \%$ for 8-pCPT-treated slices $120 \mathrm{~min}$ after LFS; Fig. 6A). Thus, 8-pCPT does not significantly alter synaptic strength following $5-\mathrm{Hz}$ stimulation for $3 \mathrm{~min}$. This result is in contrast to the enhancement of synaptic strength seen after ISO application. To investigate the molecular basis of this difference, we used pharmacologic inhibition of phosphatases. Previous studies have shown that inhibition of phosphatase activity gates the induction of LTP (Thomas et al. 1996; Blitzer et al. 1998; Brown et al. 2000). However, we found that inhibition of phosphatases with okadaic acid (OA) $(1 \mu \mathrm{M})$ permitted the induction but not the maintenance of LTP. LTP induced by applying LFS at 5 $\mathrm{Hz}$ for $3 \mathrm{~min}$ in OA-treated slices was decremental, with a mean fEPSP slope of $101.5 \pm 3.9 \% 120 \mathrm{~min}$ after LFS (Fig. 6B). Similarly, LTP elicited by one train of HFS did not differ between OA-treated and control slices (mean fEPSP slopes were $104.3 \pm 4.8 \%$ in OA-treated slices and $109.2 \pm 5.6 \%$ in control slices 120 min after LFS; Fig. 6D). These results suggest that phosphatase inhibition lowers the threshold for LTP induction without affecting LTP stability. As such, we examined whether application of 8-pCPT facilitates the maintenance of LTP induced by LFS during phosphatase inhibition. Application of either ISO or 8-pCPT to OA-treated slices during LFS resulted in long-lasting LTP (mean fEPSP slopes were $132.5 \pm 5.8 \%$ and $131.6 \pm 10.0 \%$ for ISO and 8-pCPTtreated slices, respectively, $120 \mathrm{~min}$ after LFS; Fig. 6C). Maintenance of this LTP was significantly enhanced compared with LTP generated by LFS alone applied to OA-treated slices $(P<0.05$; Fig. $6 \mathrm{E})$. Overall, these results suggest that application of 8-pCPT can facilitate the maintenance of LTP when the threshold for LTP induction is decreased by chemical inhibition of phosphatases. 


\section{Discussion}

We have examined the role of the cAMP-activated GEF Epac in hippocampal synaptic plasticity. Our data show that an Epac agonist, 8-pCPT, enhances the maintenance of various forms of LTP in area CA1, without exerting significant effects on basal synaptic transmission or initial LTP induction. Short-lasting, protein synthesis-independent LTP was converted into a stable, protein synthesis-dependent form of LTP by activation of Epac. We also demonstrated that the mechanism for this Epac-dependent LTP enhancement involves recruitment of ERK.

Numerous signaling molecules contribute to the expression of LTP (Sanes and Lichtman 1999). These molecules modulate various neuronal properties, including basal synaptic transmission and the capacity for LTP induction or maintenance. We found that 8-pCPT did not affect baseline synaptic responses or the initial magnitude of potentiation generated by one train of HFS. However, 8-pCPT significantly enhanced the maintenance of LTP generated by one train of HFS. Thus, pairing 8-pCPT with a stimulation protocol that is normally unable to elicit longlasting potentiation of synaptic strength facilitated the expression of stable LTP. Importantly, the 8-pCPT-dependent enhancement of LTP was not blocked by pretreatment with a PKA inhibitor, confirming that this enhancement is not mediated by PKA. Taken together, these results suggest that activation of Epac facilitates the stabilization of LTP.

The inability of 8-pCPT to facilitate LTP induction suggests that this signaling pathway may preferentially modulate LTP when sufficient synaptic stimulation is concurrently applied. This notion is supported by our observation that 8-pCPT can also facilitate the maintenance of LTP induced by LFS when phosphatases are inhibited. Phosphatases gate LTP induction, such that inhibition of phosphatases can substitute for cAMP pathway activation (Blitzer et al. 1998). We found that pretreatment with the phosphatase inhibitor OA permitted induction of decremental LTP by LFS. Pairing LFS with Epac in slices pretreated with OA generated long-lasting LTP. Facilitation of LTP by a drug known to activate Epac requires concomitant synaptic stimulation, in either electrical or chemical form. This observation suggests that activation of Epac may stabilize LTP induced by different mechanisms, as long as sufficient synaptic stimulation is provided.

Long-term changes in synaptic strength are distinguished from more transient forms of plasticity by their dependence on macromolecular synthesis (Krug et al. 1984; Frey et al. 1988, 1996; Nguyen et al. 1994; Kandel 2001). We have shown here that the enhanced maintenance of LTP resulting from application of an Epac agonist during LTP induction requires protein synthesis, but not transcription. These results support the notion that translational activation of pre-existing dendritic mRNAs can sustain specific forms of synaptic plasticity. For instance, $\beta$-adrenergic receptorenhanced LTP (Gelinas and Nguyen 2005), LTD induced by mGluR activation (Huber et al. 2001), and facilitation elicited by brain-derived neurotrophic factor (BDNF) (Kang and Schuman 1996) are forms of synaptic plasticity that do

not require transcription. Similarly, LTP generated by multiple trains of HFS can be stabilized by local protein synthesis for $\sim 3 \mathrm{~h}$ post-induction (Cracco et al. 2005; Tsokas et al. 2005). Our present findings establish a putative cAMP-activated signaling pathway that can facilitate induction of translation-dependent, transcription-independent LTP. As such, Epac activation could occur downstream of Gs-protein-coupled receptors or $\mathrm{Ca}^{2+}$-activated adenylyl cyclases to participate in stabilization of LTP. Indeed, overexpression of Epac potentiates the activation of ERK in response to stimulation of the Gs-protein coupled $5-\mathrm{HT}_{7 \mathrm{~A}}$ receptors (Lin et al. 2003). Our results further support this notion by demonstrating that the maintenance of $\beta$-adrenergic receptordependent LTP is occluded by prior expression of 8-pCPTenhanced LTP. Thus, these forms of LTP appear to share similar underlying mechanisms.

Our results also reveal that Epac activates ERK, and this activation is required for the persistence of Epac-enhanced LTP. ERK signaling is required for numerous forms of LTP and memory (Sweatt 2004; Thomas and Huganir 2004) and is specifically implicated in translational control of plasticity (Banko et al. 2004, 2006; Gallagher et al. 2004; Kelleher et al. 2004). ERK activation downstream of Epac has been observed in non-neuronal cells (Keiper et al. 2004; Wang et al. 2006). However, the persistence of our 8-pCPT-enhanced LTP was not associated with an increase in either the amount or duration of ERK activation. The ability of Epac to activate ERK has been linked to its localization at the plasma membrane, with perinuclear Epac unable to activate ERK (Wang et al. 2006). Our use of a multiwire stimulation electrode allowed us to activate more synapses than with a conventional single wire electrode. However, our analysis sampled "bulk" ERK (located throughout the cytoplasm and at the plasma membrane) after application of 8-pCPT paired with tetanus, and it is possible that additional ERK activation elicited by Epac at the plasma membrane could not be detected in the presence of substantial cytoplasmic ERK activation elicited by tetanus alone. It is also possible that 8-pCPT application and tetanus engage similar

A.

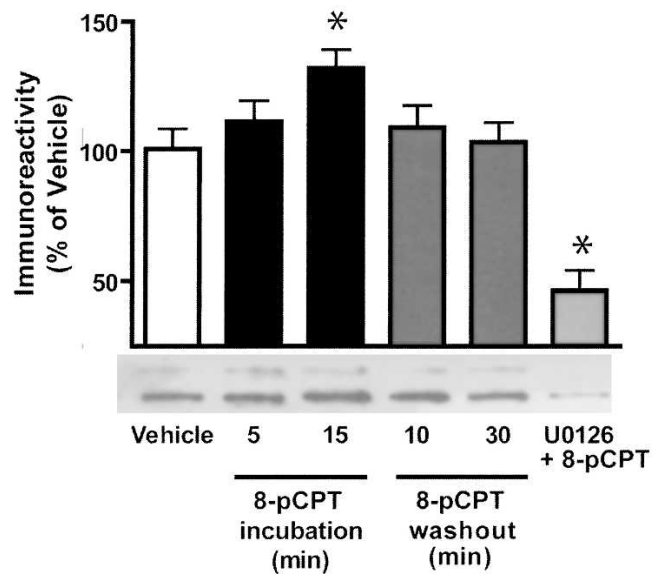

Figure 4. 8-pCPT increases ERK phosphorylation. Quantitative Western blot analysis of phospho-ERK immunoreactivity in hippocampal CA1 slices exposed to 8-pCPT. (A) Representative phospho-ERK Western blot depicting changes in immunoreactivity resulting from 5 or 15 min of 8-pCPT incubation, 10 or $30 \mathrm{~min}$ of washout of 8-pCPT (15 min incubation), and pairing 8-pCPT with U0126 pretreatment. 8-pCPT treatment led to a transient increase in phospho-ERK immunoreactivity that was blocked by pre-treatment with U0126. (B) Representative phospho-ERK Western blot depicting changes in immunoreactivity following 10 min baseline stimulation (vehicle), 5 min after HFS (100 Hz, $1 \mathrm{sec}$ ) delivered alone, and $5 \mathrm{~min}$ (HFS+8-pCPT) and $30 \mathrm{~min}(30 \mathrm{~min})$ after delivery of HFS paired with 8-pCPT. 8-pCPT did not enhance the HFS-induced phospho-ERK immunoreactivity. Data are expressed as mean \pm SEM. The asterisks show significant difference from the vehicle mean as determined by paired $t$-test. 
A.

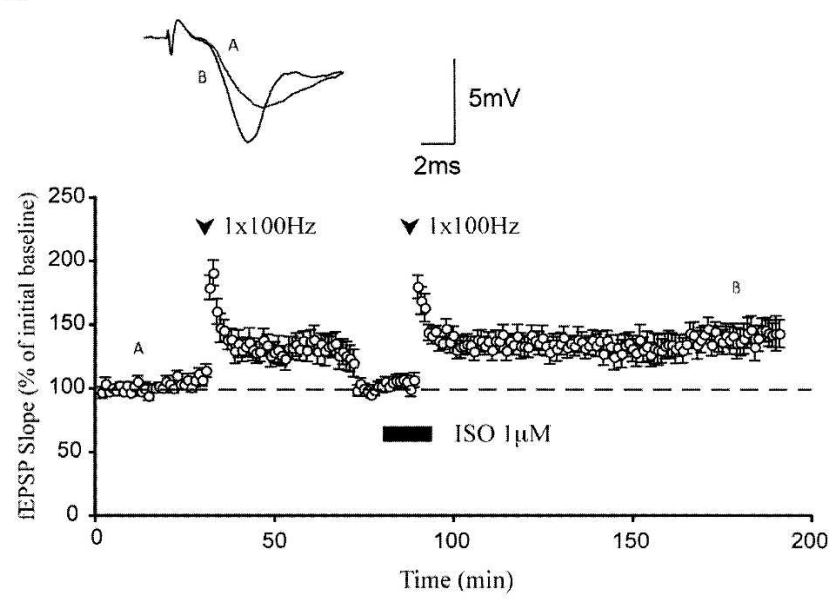

B.
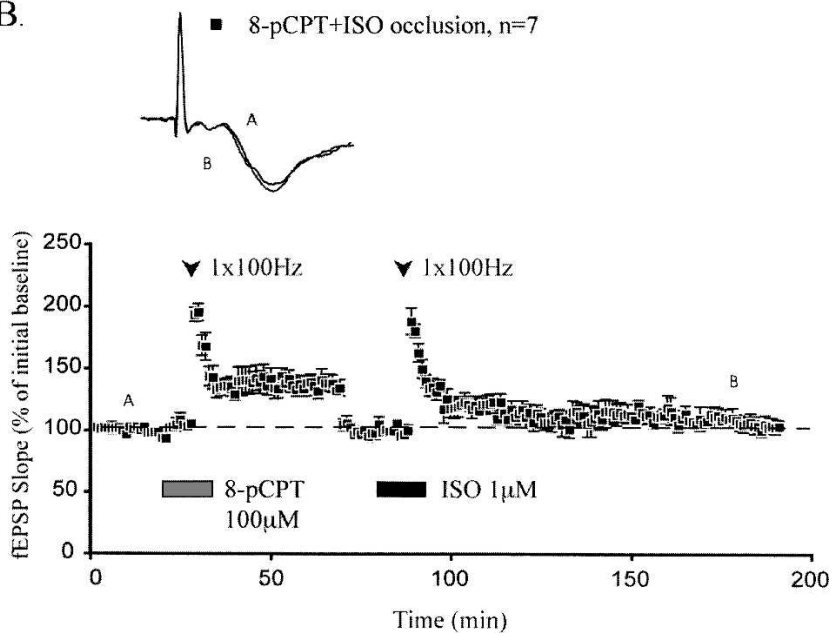

Figure 5. LTP generated by pairing 8 -pCPT with $1 \times 100 \mathrm{~Hz}$ occludes $\beta$-adrenergic receptor-dependent LTP. $(A) 1 \times 100 \mathrm{~Hz}$ stimulation alone does not occlude subsequent maintenance of LTP generated by pairing application of ISO with $1 \times 100 \mathrm{~Hz}$ stimulation. At $120 \mathrm{~min}$ after ISO $+1 \times 100 \mathrm{~Hz}$, fEPSP slopes were potentiated significantly above the reset baseline. (B) Pairing 8-pCPT with $1 \times 100 \mathrm{~Hz}$ stimulation generates LTP that occludes subsequent maintenance of LTP generated by pairing application of ISO with $1 \times 100 \mathrm{~Hz}$ stimulation. At $120 \mathrm{~min}$ after ISO $+1 \times 100 \mathrm{~Hz}$, fEPSP slopes had decayed nearly to the reset baseline. All sample traces were taken at time points $A$ and $B$ on graphs. Calibration bars: $5 \mathrm{mV}, 2 \mathrm{msec}$.

pools of ERK, such that pretreatment with 8-pCPT activates this pool of ERK, and no substantial further increase is possible with subsequent tetanic stimulation. We observed that 8-pCPTenhanced LTP is blocked by a protein synthesis inhibitor and thus is likely mediated by translational control mechanisms. This finding supports the notion that activation of specific pools of ERK, rather than global enhancement of ERK activation, is critical for expression of this form of LTP. Further research using optical probes of Epac activity is needed to test this notion. Also, development of specific pharmacological inhibitors of Epac, and mouse knockouts of Epac, are needed to definitively prove that Epac is required for synaptic plasticity. Presently, there are no specific Epac inhibitors or genetically engineered mice that lack Epac (Bos 2006).

Epac-dependent facilitation of LTP maintenance in the hip- pocampus has potential physiological and behavioral ramifications. Long-lasting hippocampal LTP is strongly correlated with explicit LTM (Doyere and Laroche 1992; Bourtchuladze et al. 1994; Abel et al. 1997; Genoux et al. 2002). cAMP is an important second messenger involved in both synaptic plasticity and memory (Frey et al. 1993; Abel et al. 1997; Nguyen and Woo 2003). Thus, activation of Epac by cAMP in CA1 neurons is likely to exert significant functional consequences. Epac could link cAMP to ERK activation in CA1 neurons, potentially allowing for rapid regulation of hippocampal long-term synaptic plasticity and modulation of memory. Epac expression levels are altered in several brain structures in Alzheimer's disease (McPhee et al. 2005), and Epac signaling is implicated in modulating key proteins involved in neurodegenerative conditions (Maillet et al. 2003). Our results establish a novel role for Epac in boosting long-lasting hippocampal synaptic plasticity.

\section{Materials and Methods}

\section{Electrophysiology}

Female C57BL/6 mice (8-13 wk old; Charles River) were sacrificed and decapitated. Transverse hippocampal slices $(400 \mu \mathrm{M})$ were obtained and transferred to an interface recording chamber held at $28^{\circ} \mathrm{C}$. The artificial cerebrospinal fluid (ACSF) used for dissection and perfusion (1-2 $\mathrm{mL} / \mathrm{min})$ contained: $124 \mathrm{mM} \mathrm{NaCl}, 4.4$ $\mathrm{mM} \mathrm{KCl}, 1.3 \mathrm{mM} \mathrm{MgSO}_{4}, 1.0 \mathrm{mM} \mathrm{NaH}_{2} \mathrm{PO}_{4}, 26.2 \mathrm{mM} \mathrm{NaHCO}_{3}$, $2.5 \mathrm{mM} \mathrm{CaCl}_{2}, 10 \mathrm{mM}$ glucose, aerated with $95 \% \mathrm{O}_{2}$ and $5 \%$ $\mathrm{CO}_{2}$. After at least $1 \mathrm{~h}$ of recovery, fEPSPs were evoked in stratum radiatum using a bipolar nickel-chromium stimulating electrode and recorded using a glass microelectrode filled with ACSF. Baseline fEPSPs were elicited once per minute at a stimulus intensity (0.08-msec pulse width) producing fEPSP amplitudes that were $40 \%$ of maximal amplitudes. I/O data were collected by varying the intensities of seven stimuli applied to area CA1. PPF was examined by applying two pulses at interpulse intervals of 50 , 100,150 , and $200 \mathrm{msec}$. LTP was induced with one train of highfrequency stimulation $(100 \mathrm{~Hz}$ for 1 -sec duration at $40 \%$ of maximal fEPSP amplitude). LFS at $5 \mathrm{~Hz}$ for 3 min was also applied. For occlusion experiments, fEPSP slope was reset to baseline $35 \mathrm{~min}$ after tetanization by reducing stimulation intensity such that the new fEPSP slope matched the average fEPSP slope obtained during the initial $20 \mathrm{~min}$ of baseline recording. An additional $10 \mathrm{~min}$ of new "baseline" recording was then taken before drug infusion began.

\section{Drugs}

A specific Epac agonist, 8-(4-chlorophenylthio)-2'-O-methylcAMP (8-pCPT, $100 \mu \mathrm{M}$; Axxora) (Enserink et al. 2002) was prepared as a concentrated stock solution at $50 \mathrm{mM}$ in DMSO. 8-pCPT was applied to slices for a total duration of $15 \mathrm{~min}$. 8 -pCPT is highly membrane-permeant and can effectively and selectively activate Epac in neuronal and non-neuronal cell lines at the concentration and duration of application used here (Enserink et al. 2002; Lin et al. 2003). The $\beta$-adrenergic receptor agonist ISO $[\mathrm{R}(-)$-isoproterenol (+)-bitartrate, $1 \mu \mathrm{M}$; SigmaAldrich Canada] was prepared daily as a $1 \mathrm{mM}$ stock solution in distilled water. ISO was applied to slices for a total duration of 15 min. A translation inhibitor, emetine $(20 \mu \mathrm{M}$; Sigma-Aldrich Canada), and a transcription inhibitor, ActD ( $25 \mu \mathrm{M}$; Bioshop Canada) were prepared as concentrated stock solutions at $20 \mathrm{mM}$ in distilled water and $25 \mathrm{mM}$ in DMSO, respectively. The concentrations of these inhibitors have been shown to be effective for blocking macromolecular synthesis in hippocampal slices (Stanton and Sarvey 1984; Nguyen et al. 1994). An ERK inhibitor, U0126, $(20 \mu \mathrm{M}$; Bioshop Canada) was prepared as a concentrated stock solution at $20 \mathrm{mM}$ in DMSO, and a PKA inhibitor KT-5720 ( $1 \mu \mathrm{M}$; Sigma) was prepared as a concentrated stock solution at 1 $\mathrm{mM}$ in DMSO. Each drug was diluted to its final concentration in ACSF and bath applied. These drugs were applied 20 min before 
A.

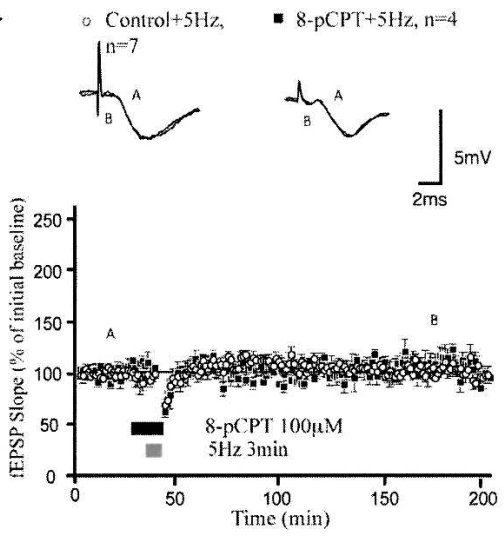

C.
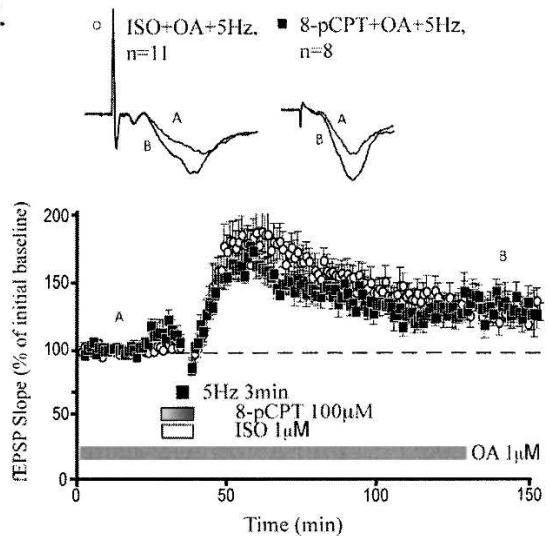

E.

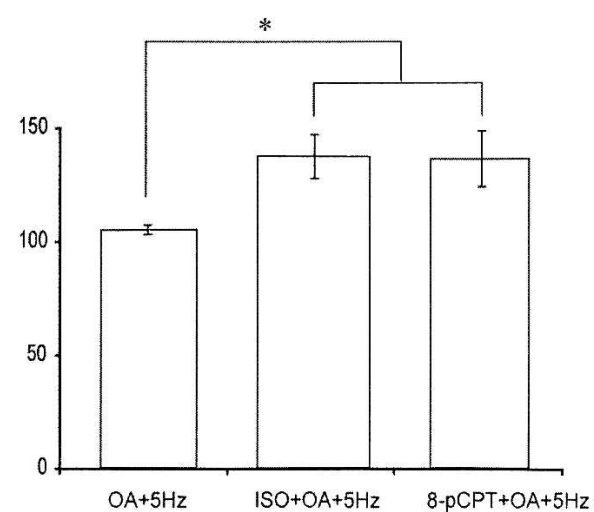

Figure 6. 8-pCPT enhances maintenance of chemically induced LTP. (A) Pairing 8-pCPT with 5- $\mathrm{Hz}$ stimulation has no long-term effect on synaptic strength. (B) Treatment with okadaic acid (OA), a protein phosphatase inhibitor, permits the induction of decremental LTP in response to $5-\mathrm{Hz}$ stimulation. (C) Application of ISO, a $\beta$-adrenergic agonist, or 8-pCPT during $5-\mathrm{Hz}$ stimulation enhances maintenance of LTP in OA-treated slices. $(D)$ Treatment with OA does not alter LTP generated by $1 \times 100 \mathrm{~Hz}$ stimulation. (E) Summary histogram comparing levels of potentiation $120 \mathrm{~min}$ after $5-\mathrm{Hz}$ stimulation $\left({ }^{*} P<0.05\right)$. All sample traces were taken at time points $A$ and $B$ on graphs. Calibration bars: $5 \mathrm{mV}, 2 \mathrm{msec}(3 \mathrm{mV}, 2 \mathrm{msec}$ for slices incubated in $\mathrm{OA})$.

8-pCPT application, were present throughout 8-pCPT application, and were discontinued 10 min after 8-pCPT washout began. The final concentration of DMSO did not affect basal synaptic transmission or LTP (data not shown). Sodium OA ( $1 \mu \mathrm{M}$; Sigma) was prepared as a concentrated $1 \mathrm{mM}$ stock solution in distilled water. Hippocampal slices were incubated in OA for 90-180 min before commencing experiments. Experiments were performed blind, with application of drug interleaved with application of drug-free ACSF controls. Dimmed light conditions were used for drug experiments due to the light-sensitive nature of some drugs.

\section{Data analysis}

PPF, I/O, and LTP were assessed in the Schaeffer collateral pathway of hippocampal slices. For PPF analysis, Student's $t$-test was used to compare percentage facilitation between groups at each interpulse interval. I/O analysis was conducted by plotting presynaptic fiber volley amplitudes and fEPSP slopes, then determining linear regression values. Linear regressions between groups were compared using Student's $t$-test. For LTP experiments, Student's $t$-test was used to statistically compare means of fEPSP slopes between two groups $120 \mathrm{~min}$ after the experimental protocol commenced. Welch correction was applied when standard deviations of compared groups differed significantly. The Kruskal-Wallis test followed by Dunn's multiple comparisons was used to compare means of three or more groups. Significance criteria was $P<0.05$ in all cases. All values are shown as mean \pm SEM, with $n$ indicating the number of slices.

\section{Hippocampal slice preparation and drug treatment for Western blot analysis}

Six- to 8-wk-old male C57BL/6 mice were decapitated. Their brains were dissected rapidly and placed into ice-cold cutting saline containing: $110 \mathrm{mM}$ sucrose, $60 \mathrm{mM} \mathrm{NaCl}, 3 \mathrm{mM} \mathrm{KCl}, 1.25 \mathrm{mM}$ $\mathrm{NaH}_{2} \mathrm{PO}_{4}, 28 \mathrm{mM} \mathrm{NaHCO}, 5 \mathrm{mM}$ Dglucose, $0.5 \mathrm{mM} \mathrm{CaCl}_{2}, 7 \mathrm{mM} \mathrm{MgCl}_{2}$, and $0.6 \mathrm{mM}$ ascorbate, saturated with $95 \% \mathrm{O}_{2} / 5 \% \mathrm{CO}_{2}$. Then, 400- $\mu \mathrm{m}$ transverse slices were prepared with a tissue chopper. Slices were transferred immediately into a 1:1 mix of cutting saline and ACSF containing (in $\mathrm{mM}$ ): $125 \mathrm{mM}$ $\mathrm{NaCl}, 2.5 \mathrm{mM} \mathrm{KCl}, 1.25 \mathrm{mM} \mathrm{NaH} \mathrm{PO}_{4}$, $25 \mathrm{mM} \mathrm{NaHCO}, 25 \mathrm{mM}$ D-glucose, 2 $\mathrm{mM} \mathrm{CaCl}$, and $1 \mathrm{mM} \mathrm{MgCl}_{2}$, saturated with $95 \% \mathrm{O}_{2}, 5 \% \mathrm{CO}_{2}$ and maintained at room temperature for at least $30 \mathrm{~min}$. The slices then were transferred to ACSF at $32^{\circ} \mathrm{C}$ in a submersion chamber for 1.5 $\mathrm{h}$ before pharmacological stimulation. MEK inhibitor (U0126, $20 \mu \mathrm{M}$ ) was preincubated with the slices $30 \mathrm{~min}$ before the addition of agonist. The samples were collected following $10 \mathrm{~min}$ of baseline stimulation (vehicle), 5 min after delivery of HFS $(100 \mathrm{~Hz}, 1 \mathrm{sec})$ alone (HFS), and 5 min (HFS+drug) and $30 \mathrm{~min}$ (30 min) after delivery of HFS paired with the agonist. For experiments using a single train of $100-\mathrm{Hz}$ high-frequency stimulation, we used an 8-wire Teflon-coated platinum stimulation electrode. The surface area of the electrode tip was placed within area CA3 during stimulation. Slices were immediately frozen on dry ice following pharmacological manipulations. The CA1 subregions were microdissected and stored at $-80^{\circ} \mathrm{C}$ until assayed. CA1 subregions from four to six slices were pooled for each experimental condition. 


\section{Quantitative Western blot analysis}

Equivalent amounts of protein for each sample were resolved in $10 \%$ SDS-polyacrylamide gels and transferred to polyvinlyidene difluoride (PVDF) membranes. The PVDF membranes were incubated with reversible MemCode protein stain to confirm equal loading and transfer. Membranes were blocked in Tris-buffered saline containing $0.05 \%$ Tween 20 and $0.24 \%$ I-Block (Tropix) and then incubated with phosphor-ERK antibody (1:5000 dilution; Cell Signaling) for $1 \mathrm{~h}$ at room temperature. This was followed by incubation with horseradish peroxidase-linked goat anti-rabbit IgG (1:2500 dilution; Promega) for $1 \mathrm{~h}$ at room temperature. Membranes were developed using enhanced chemiluminescence (Amersham Biosciences). The bands of each Western blot were quantified from film exposures in the linear range for the phosphor-ERK antibody and normalized to the MemCode membrane staining with densitometry using a desktop scanner and NIH Image software to determine the amount of immunoreactivity. GraphPad Prism data analysis software was used for graph production and statistical analysis. Statistical analysis via paired $t$-test was used, with $P<0.05$ as the significance criterion.

\section{Acknowledgments}

This work was supported by NIH grants NS034007 and NS047384 (E.K.), by the FRAXA Research Foundation (E.K.), and by grants from the Canadian Institutes of Health Research (P.V.N.) and the Alberta Heritage Foundation for Medical Research (P.V.N.). J.G. was supported by M.D.-Ph.D. Studentships from the CIHR and AHFMR. P.N. is a Faculty Senior Scholar of the Alberta Heritage Foundation and a Distinguished International Scholar of the University of Pennsylvania.

\section{References}

Abel, T., Nguyen, P.V., Barad, M., Deuel, T.A., Kandel, E.R., and Bourtchouladze, R. 1997. Genetic demonstration of a role for PKA in the late phase of LTP and in hippocampus-based long-term memory. Cell 88: 615-626.

Abraham, W.C., Logan, B., Greenwood, J.M., and Dragunow, M. 2002. Induction and experience-dependent consolidation of stable long-term potentiation lasting months in the hippocampus. $J$. Neurosci. 22: 9626-9634.

Banko, J.L., Hou, L., and Klann, E. 2004. NMDA receptor activation results in PKA- and ERK-dependent Mnk1 activation and increased eIF4E phosphorylation in hippocampal area CA1. J. Neurochem. 91: $462-470$.

Banko, J.L., Hou, L., Poulin, F., Sonenberg, N., and Klann, E. 2006. Regulation of eukaryotic initiation factor $4 \mathrm{E}$ by converging signaling pathways during metabotropic glutamate receptor-dependent long-term depression. J. Neurosci. 26: 2167-2173.

Bliss, T.V. and Collingridge, G.L. 1993. A synaptic model of memory: Long-term potentiation in the hippocampus. Nature 361: 31-39.

Blitzer, R.D., Connor, J.H., Brown, G.P., Wong, T., Shenolikar, S., Iyengar, R., and Landau, E.M. 1998. Gating of CaMKII by cAMP-regulated protein phosphatase activity during LTP. Science 280: $1940-1942$.

Bos, J.L. 2006. Epac proteins: Multi-purpose cAMP targets. Trends Biochem. Sci. 31: 680-686.

Bourtchuladze, R., Frenguelli, B., Blendy, J., Cioffi, D., Schutz, G., and Silva, A.J. 1994. Deficient long-term memory in mice with a targeted mutation of the cAMP-responsive element-binding protein. Cell 79: $59-68$.

Braunewell, K.H. and Manahan-Vaughan, D. 2001. Long-term depression: A cellular basis for learning? Rev. Neurosci. 12: 121-140.

Brown, G.P., Blitzer, R.D., Connor, J.H., Wong, T., Shenolikar, S., Iyengar, R., and Landau, E.M. 2000. Long-term potentiation induced by theta frequency stimulation is regulated by a protein phosphatase-1-operated gate. I. Neurosci. 20: 7880-7887.

Cracco, J.B., Serrano, P., Moskowitz, S.I., Bergold, P.J., and Sacktor, T.C. 2005. Protein synthesis-dependent LTP in isolated dendrites of CA1 pyramidal cells. Hippocampus 15: 551-556.

Deadwyler, S.A., Dunwiddie, T., and Lynch, G. 1987. A critical level of protein synthesis is required for long-term potentiation. Synapse 1: 90-95.

de Rooij, J., Zwartkruis, F.J., Verheijen, M.H., Cool, R.H., Nijman, S.M., Wittinghofer, A., and Bos, J.L. 1998. Epac is a Rap1 guanine-nucleotide-exchange factor directly activated by cyclic AMP. Nature 396: 474-477.

Doyere, V. and Laroche, S. 1992. Linear relationship between the maintenance of hippocampal long-term potentiation and retention of an associative memory. Hippocampus 2: 39-48.

Duffy, S.N., Craddock, K.J., Abel, T., and Nguyen, P.V. 2001. Environmental enrichment modifies the PKA-dependence of hippocampal LTP and improves hippocampus-dependent memory. Learn. Mem. 8: 26-34.

Enserink, J.M., Christensen, A.E., de Rooij, J., van Triest, M., Schwede, F., Genieser, H.G., Doskeland, S.O., Blank, J.L., and Bos, J.L. 2002. A novel Epac-specific cAMP analogue demonstrates independent regulation of Rap1 and ERK. Nat. Cell Biol. 4: 901-906.

Frey, U., Krug, M., Reymann, K.G., and Matthies, H. 1988. Anisomycin, an inhibitor of protein synthesis, blocks late phases of LTP phenomena in the hippocampal CA1 region in vitro. Brain Res. 452: $57-65$.

Frey, U., Huang, Y.Y., and Kandel, E.R. 1993. Effects of cAMP simulate a late stage of LTP in hippocampal CA1 neurons. Science 260: $1661-1664$.

Frey, U., Frey, S., Schollmeier, F., and Krug, M. 1996. Influence of actinomycin D, a RNA synthesis inhibitor, on long-term potentiation in rat hippocampal neurons in vivo and in vitro. $J$. Physiol. 490: 703-711.

Gallagher, S.M., Daly, C.A., Bear, M.F., and Huber, K.M. 2004. Extracellular signal-regulated protein kinase activation is required for metabotropic glutamate receptor-dependent long-term depression in hippocampal area CA1. J. Neurosci. 24: 4859-4864.

Gelinas, J.N. and Nguyen, P.V. 2005. $\beta$-Adrenergic receptor activation facilitates induction of a protein synthesis-dependent late phase of long-term potentiation. I. Neurosci. 25: 3294-3303.

Genoux, D., Haditsch, U., Knobloch, M., Michalon, A., Storm, D., and Mansuy, I.M. 2002. Protein phosphatase 1 is a molecular constraint on learning and memory. Nature 418: 970-975.

Huang, Y.Y., Nguyen, P.V., Abel, T., and Kandel, E.R. 1996. Long-lasting forms of synaptic potentiation in the mammalian hippocampus. Learn. Mem. 3: 74-85.

Huber, K.M., Roder, J.C., and Bear, M.F. 2001. Chemical induction of mGluR5- and protein synthesis-dependent long-term depression in hippocampal area CA1. J. Neurophysiol. 86: 321-325.

Johnson-Farley, N.N., Kertesy, S.B., Dubyak, G.R., and Cowen, D.S. 2005. Enhanced activation of Akt and extracellular-regulated kinase pathways by simultaneous occupancy of Gq-coupled 5-HT2A receptors and Gs-coupled 5-HT7A receptors in PC12 cells. J. Neurochem. 92: 72-82.

Kandel, E.R. 2001. The molecular biology of memory storage: A dialogue between genes and synapses. Science 294: 1030-1038.

Kang, H. and Schuman, E.M. 1996. A requirement for local protein synthesis in neurotrophin-induced hippocampal synaptic plasticity. Science 273: 1402-1406.

Kawasaki, H., Springett, G.M., Mochizuki, N., Toki, S., Nakaya, M., Matsuda, M., Housman, D.E., and Graybiel, A.M. 1998. A family of cAMP-binding proteins that directly activate Rap1. Science 282: 2275-2279.

Keiper, M., Stope, M.B., Szatkowski, D., Böhm, A., Tysack, K., Vom Dorp, F., Saur, O., Oude, Weernink, P.A., Evellin, S., Jakobs, K.H., et al. 2004. Epac- and $\mathrm{Ca}^{2+}$-controlled activation of Ras and extracellular signal-regulated kinases by Gs-coupled receptors. J. Biol. Chem. 279: 46497-46508.

Kelleher III, R.J., Govindarajan, A., Jung, H.Y., Kang, H., and Tonegawa, S. 2004. Translational control by MAPK signaling in long-term synaptic plasticity and memory. Cell 116: 467-479.

Krug, M., Lossner, B., and Ott, T. 1984. Anisomycin blocks the late phase of long-term potentiation in the dentate gyrus of freely moving rats. Brain Res. Bull. 13: 39-42.

Lin, S.L., Johnson-Farley, N.N., Lubinsky, D.R., and Cowen, D.S. 2003. Coupling of neuronal 5-HT7 receptors to activation of extracellular-regulated kinase through a protein kinase A-independent pathway that can utilize Epac. J. Neurochem. 87: 1076-1085.

Lynch, M.A. 2004. Long-term potentiation and memory. Physiol. Rev. 84: $87-136$

Maillet, M., Robert, S.J., Cacquevel, M., Gastineau, M., Vivien, D., Bertoglio, J., Zugaza, J.L., Fischmeister, R., and Lezoualc'h, F. 2003. Crosstalk between Rap1 and Rac regulates secretion of sAPP $\alpha$. Nat. Cell Biol. 5: 633-639.

McPhee, I., Gibson, L.C., Kewney, J., Darroch, C., Stevens, P.A., Spinks, D., Cooreman, A., and MacKenzie, S.J. 2005. Cyclic nucleotide signalling: A molecular approach to drug discovery for Alzheimer's disease. Biochem. Soc. Trans. 33: 1330-1332.

Moser, E.I., Krobert, K.A., Moser, M.B., and Morris, R.G. 1998. Impaired spatial learning after saturation of long-term potentiation. Science 
281: 2038-2042.

Nguyen, P.V. and Kandel, E.R. 1996. A macromolecular synthesis-dependent late phase of long-term potentiation requiring cAMP in the medial perforant pathway of rat hippocampal slices. $J$. Neurosci. 16: 3189-3198.

Nguyen, P.V. and Woo, N.H. 2003. Regulation of hippocampal synaptic plasticity by cyclic AMP-dependent protein kinases. Prog. Neurobiol. 71: 401-437.

Nguyen, P.V., Abel, T., and Kandel, E.R. 1994. Requirement of a critical period of transcription for induction of a late phase of LTP. Science 265: $1104-1107$.

Sanes, J.R. and Lichtman, J.W. 1999. Can molecules explain long-term potentiation? Nat. Neurosci. 2: 597-604.

Schmitt, J.M., Guire, E.S., Saneyoshi, T., and Soderling, T.R. 2005 Calmodulin-dependent kinase kinase/calmodulin kinase I activity gates extracellular-regulated kinase-dependent long-term potentiation. I. Neurosci. 25: 1281-1290.

Stanton, P.K. and Sarvey, J.M. 1984. Blockade of long-term potentiation in rat hippocampal CA1 region by inhibitors of protein synthesis. $J$. Neurosci. 4: 3080-3088.

Sweatt, J.D. 2004. Mitogen-activated protein kinases in synaptic plasticity and memory. Curr. Opin. Neurobiol. 14: 311-317.

Thomas, G.M. and Huganir, R.L. 2004. MAPK cascade signalling and synaptic plasticity. Nat. Rev. Neurosci. 5: 173-183.

Thomas, M.J., Moody, T.D., Makhinson, M., and O'Dell, T.J. 1996. Activity-dependent $\beta$-adrenergic modulation of low frequency stimulation induced LTP in the hippocampal CA1 region. Neuron 17: 475-482.

Traver, S., Marien, M., Martin, E., Hirsch, E.C., and Michel, P.P. 2006 The phenotypic differentiation of locus coeruleus noradrenergic neurons mediated by BDNF is enhanced by corticotrophin releasing factor through the activation of a cAMP-dependent signaling pathway. Mol. Pharmacol. 70: 30-40.
Tsien, J.Z., Huerta, P.T., and Tonegawa, S. 1996. The essential role of hippocampal CA1 NMDA receptor-dependent synaptic plasticity in spatial memory. Cell 87: 1327-1338.

Tsokas, P., Grace, E.A., Chan, P., Ma, T., Sealfon, S.C., Iyengar, R., Landau, E.M., and Blitzer, R.D. 2005. Local protein synthesis mediates a rapid increase in dendritic elongation factor $1 \mathrm{~A}$ after induction of late long-term potentiation. J. Neurosci. 25: 5833-5843.

Wang, Z., Dillon, T.J., Pokala, V., Mishra, S., Labudda, K., Hunter, B., and Stork, P.J. 2006. Rap1-mediated activation of extracellular signal-regulated kinases by cyclic AMP is dependent on the mode of Rap1 activation. Mol. Cell. Biol. 26: 2130-2145.

Winder, D.G., Martin, K.C., Muzzio, I.A., Rohrer, D., Chruscinski, A., Kobilka, B., and Kandel, E.R. 1999. ERK plays a regulatory role in induction of LTP by theta frequency stimulation and its modulation by $\beta$-adrenergic receptors. Neuron 24: 715-726.

Wong, S.T., Athos, J., Figueroa, X.A., Pineda, V.V., Schaefer, M.L., Chavkin, C.C., Muglia, L.J., and Storm, D.R. 1999.

Calcium-stimulated adenylyl cyclase activity is critical for hippocampus-dependent long-term memory and late phase LTP. Neuron 23: 787-798.

Woo, N.H., Duffy, S.N., Abel, T., and Nguyen, P.V. 2003. Temporal spacing of synaptic stimulation critically modulates the dependence of LTP on cyclic AMP-dependent protein kinase. Hippocampus 13: 293-300.

Zola-Morgan, S., Squire, L.R., and Amaral, D.G. 1986. Human amnesia and the medial temporal region: Enduring memory impairment following a bilateral lesion limited to field CA1 of the hippocampus. J. Neurosci. 6: 2950-2967.

Received November 6, 2007; accepted in revised form April 8, 2008. 


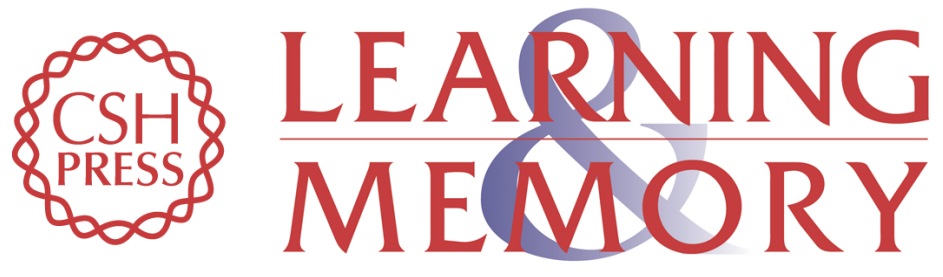

\section{Activation of exchange protein activated by cyclic-AMP enhances long-lasting synaptic potentiation in the hippocampus}

Jennifer N. Gelinas, Jessica L. Banko, Melinda M. Peters, et al.

Learn. Mem. 2008, 15:

Access the most recent version at doi:10.1101//m.830008

References This article cites 53 articles, 22 of which can be accessed free at:

http://learnmem.cshlp.org/content/15/6/403.full.html\#ref-list-1

License

Email Alerting Receive free email alerts when new articles cite this article - sign up in the box at the Service top right corner of the article or click here. 